\title{
Evaluation of Lens Distortion by the Modified Goniometric Method
}

\author{
Francis E. Washer and Walter R. Darling
}

(August 3, 1959)

\begin{abstract}
This is the third of a series of papers dealing with factors affecting the accuracy of measurment of lens distortion by various visual and photographic processes. This paper presents the results of a study of the visual modified goniometric method which employs a viewing theodolite and accurate linear scale. Sources of error are investigated and discussed. Measurements are reported on the same lens that was used in the analysis of two visual and one photographic distortion measuring processes. A comparison of results by the four different methods is given. It is concluded that accurate values of lens distortion can be obtained by the modified goniometric method provided care is taken to use centered apertures and to preserve known angular relationships between telescope pointings and successive locations.
\end{abstract}

\section{Introduction}

The accurate evaluation of radial distortion in the focal plane of airplane camera lenses has been of prime importance since the advent of mapping programs that make extensive use of photographs made with airplane cameras. Radial distortion, as herein used, is the linear displacement of an imaged point from the point where it would have been imaged if the lens were perfectly orthoscopic. This displacement is measured in the image plane of the lens along a radius drawn from the intersection point of lens axis and image plane. The presence of distortion impairs the usefulness of the photographs in precision mapping. For this reason, specifications have been generally established which set limits on the magnitude of the permissible distortion for lenses used in various types of aerial photography. To determine compliance with these specifications, the values of the distortion are measured for each lens. Various methods have been developed for making these measurements and it is important that these produce reliable results.

A study of several methods commonly used in the evaluation of lens distortion has been in progress at this Bureau for some time. The methods investigated thus far are:

A. Photographic-precision lens testing camera.

B. Visual-nodal slide optical bench with collimator.

D. Visual-inverse nodal slide bench with point or line target in rear focal plane of lens.

F. Visual-modified goniometric with linear scale in rear focal plane of lens.
In this study, measurements were made on the same lens by all four methods; the results were compared and attempts were made to locate the sources of error most likely to impair the reliability of results obtained by each method. The results of these investigations have been reported for methods $\mathrm{A}, \mathrm{B}$, and $\mathrm{D} ;{ }^{1,2}$ the present paper gives the results for method $\mathrm{F}$.

A comparison of the values of the distortion obtained by methods A, B, D, and F are given in table 1 and figure 1 . The values shown for A, B, and $D$ are the final accepted values for these methods after all known sources of error have been eliminated or minimized; the values shown for $\mathrm{F}$ are the results of a single determination before any attempt was made to reduce or eliminate nonobvious sources of error.

Examination of the values of distortion shown in part (a) of table 1 shows that while there is good agreement among corresponding values obtained by $\mathrm{A}, \mathrm{B}$, and $\mathrm{D}$, the values obtained by method $\mathrm{F}$ depart markedly from those yielded by the other three. This is shown more clearly in part (b) of table 1 where the departures for each method from the average of values $\bar{D}_{3}$, obtained by $\mathrm{A}, \mathrm{B}$, and $\mathrm{D}$ are given. The values for $\mathrm{F}$ were not included in the average as it was believed that this set of values was affected by errors markedly in excess of the random errors of the order of $\pm 2 \mu$ that affected the others. This is further justified by considering the values of the departures from the average. Here the maximum departure of any value from the average

1 F. E. Washer, W. P. Tayman, and W. R. Darling, Evaluation of lens dis tortion by visual and photographic methods, J. Research NBS 61, 509 (1958) RP2920.

RP2920. nodal slide, J. Research NBS 63C, 105 (1959). 
TABLE 1. Measured values of the distortion in microns, referred to the calibrated focal length for wide angle lens No. 3 by four different methods.

The values for A, B, and D in part (a) are final accepted values while those for $\mathrm{F}$ are for a single preliminary determination. The nominal focal length of the lens is $152 \mathrm{~mm}$. Departures from the average, $\Delta D=\bar{D}_{3}-D_{\mathrm{A}}, \bar{D}_{3}-D_{\mathrm{B}}$, etc., are shown in part (b).

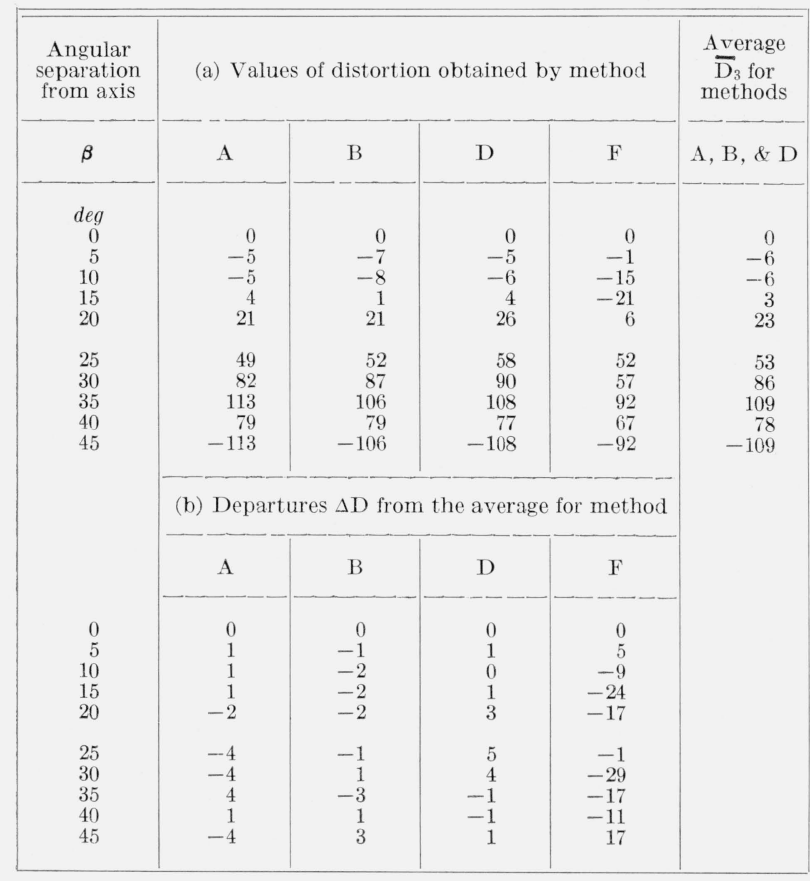

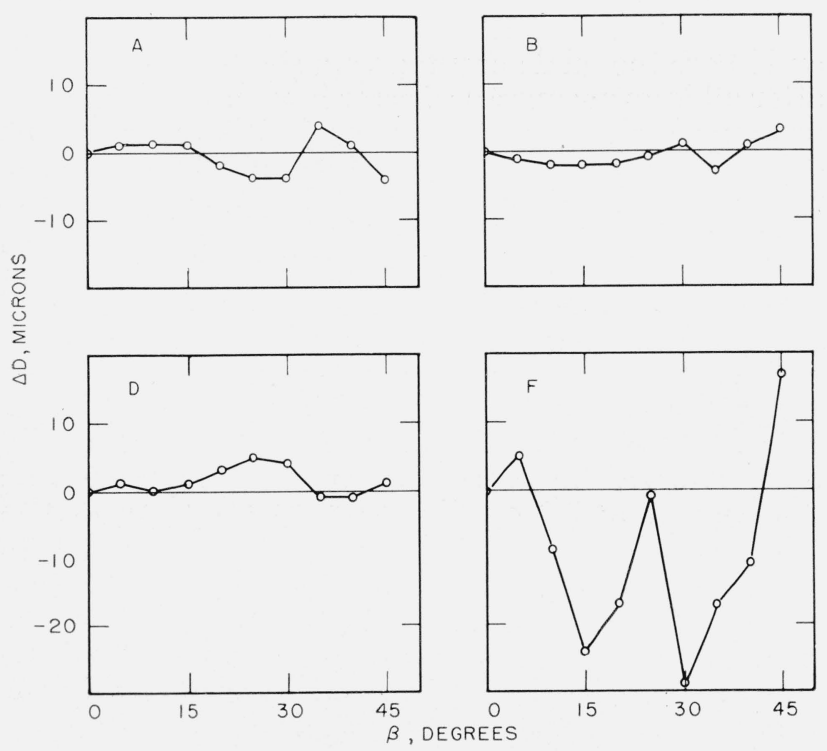

FIGURE 1. Variation of the departures, $\Delta \mathrm{D}$, from the average value of distortion, $\overline{\mathrm{D}}_{3}$, with angular separation $\beta$ from the axis.

The variation for each of the four methods are shown in the frames designated $\mathrm{A}, \mathrm{B}, \mathrm{D}$ and $\mathrm{F}$. is $\pm 5 \mu$ for $\mathrm{A}, \mathrm{B}$, and $\mathrm{D}$, while departures ranging: from -29 to $+17 \mu$ are present for method $\mathrm{F}$. This is shown still more strikingly in figure 1 , where it is clear that any random or systematic errors do not cause the values for $\mathrm{A}, \mathrm{B}$, and $\mathrm{D}$ to depart more than $\pm 5 \mu$ from the average and such departures as exist are for the most part negligible; it is also clear from figure 1 , that the values obtained by method $\mathrm{F}$ are affected by large errors somewhat cyclic in nature.

Because of the wide variance shown in the preliminary analysis, it appeared worthwhile to make a careful study of method $\mathrm{F}$ to determine the causes of these discrepancies.

\section{Study of the Modified Goniometric Method (Method F)}

\subsection{Theory}

In the usual goniometric method a device similar to a large spectrometer is used. The lens in its camera is so mounted that its front nodal point lies in the axis of rotation of the observing telescope. A scale in the focal plane of the camera is observed through the telescope and settings made on successive scale lines having known separations. For each such setting, the circular scale of the spectrometer is read in terms of angle. From the known separation of successive scale lines and the corresponding angular observations, it is possible to determine the focal length of the lens and the values of the distortion at selected points.

The modified goniometric method, as here used, is similar to the method described by Merritt. ${ }^{3}$ The relations from which values of the focal length and distortion are obtained are the same for both the usual and modified goniometric methods. If a graduated scale is located in the focal plane of the lens, and the separations of successive scale divisions from the central division assumed to be located on the lens axis are designated as $a_{1}, a_{2}, \ldots a_{n}$, and the angular separations of the corresponding divisions as viewed through the front of the lens be designated as $\beta_{1}, \beta_{2} \ldots \beta_{n}$, then

$$
f_{1}=a_{1} \cot \beta_{1} .
$$

where $f_{1}$ is the equivalent focal length of the lens. Using this value of $f$ and known values of $\beta_{1}$ the distances to the other scale divisions are computed and the distortion, $D$, is given by the relation

$$
D_{n}=a_{n}-f_{1} \tan \beta_{n} .
$$

\subsection{Description of the Apparatus}

The arrangement of the apparatus is shown in figures 2 and 3 . The lens is mounted in the nodal slide located on one leg of the T-bench. The scale, a calibrated meter bar, is placed in the focal plane of the

${ }^{3}$ E. L. Merritt, Methods of field camera calibration, Photogrammetric Eng. EVII, 610 (1951).
EV. 


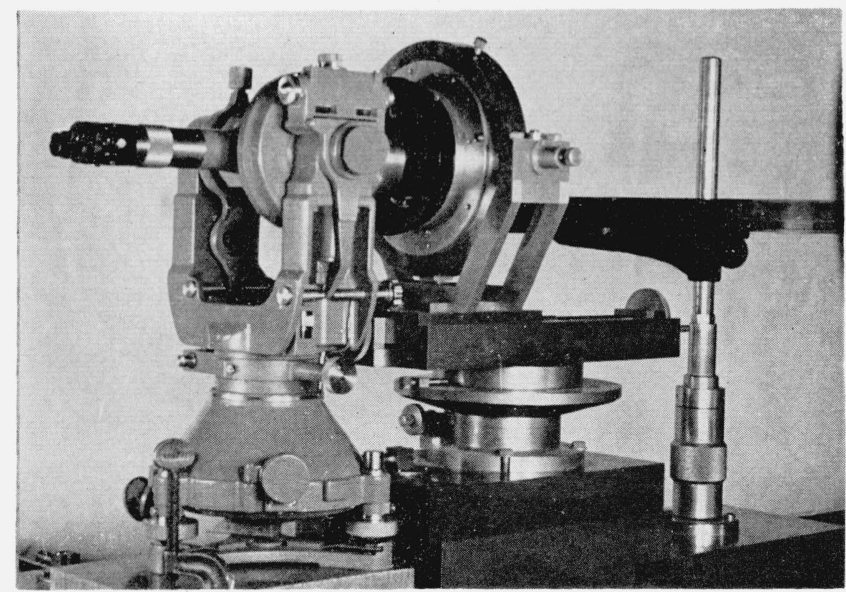

Figure 2. Arrangement of apparatus for method $F$, the modified goniometric method.

The scale at the right is located in the focal plane of the lens mounted on the nodal slide in the center of the picture. The theodolite on the left faces the front of the lens under test. For the position shown, settings can be made over the range $\beta=+11$ to -11 degrees.

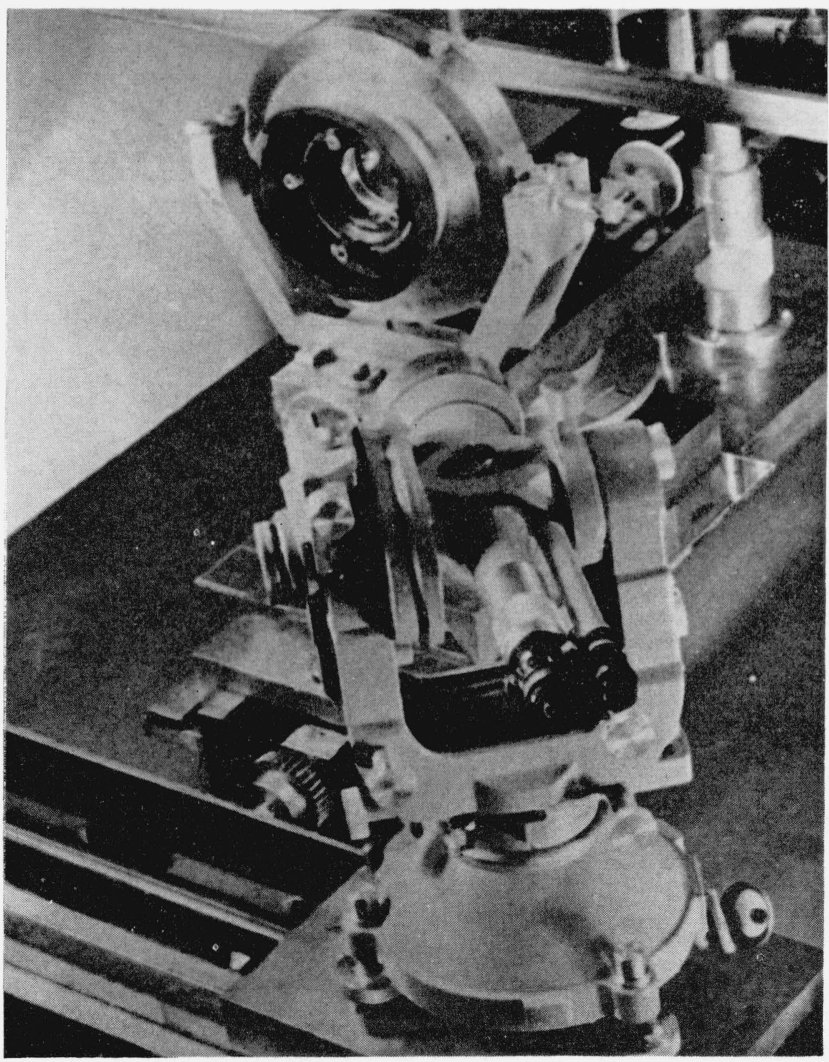

FiguRE 3. Same as figure 1 except theodolite has been displaced along the bench for making measurements in an extra axial region.

lens and placed as nearly normal as possible to the lens axis which is initially made parallel to the bench ways. The Wild theodolite is mounted on a saddle located on the cross arm of the T-bench. It is so placed that its objective is as near as feasible to the front of the lens under test. For this particular ar- rangement, settings can be made from +30 to -30 $\mathrm{mm}$ on the scale. For wide angles the arrangement shown in figure 3 is used. The appearance of the scale of the meter bar as seen through the observing telescope is shown in figure 4 for three angles of viewing.

\subsection{Results of Measurement}

It is obvious that an entire diameter of the picture area of the lens cannot be investigated for any one position of the theodolite. In order to cover all points along a single diameter, the theodolite must be traversed along the bench in a series of steps. This gives rise to alternate possibilities. The theodolite may be held in a single position with respect to the bench while a series of observations are made at selected points along the scale and then moved for successive series or it may be moved between each setting. The first process seemed easier in the early part of the work and was used. The results of measurement taken by this process are shown in the following section in table 2 .

The center of rotation of the observing telescope is separated by a very appreciable amount from a vertical line passing through the front nodal point

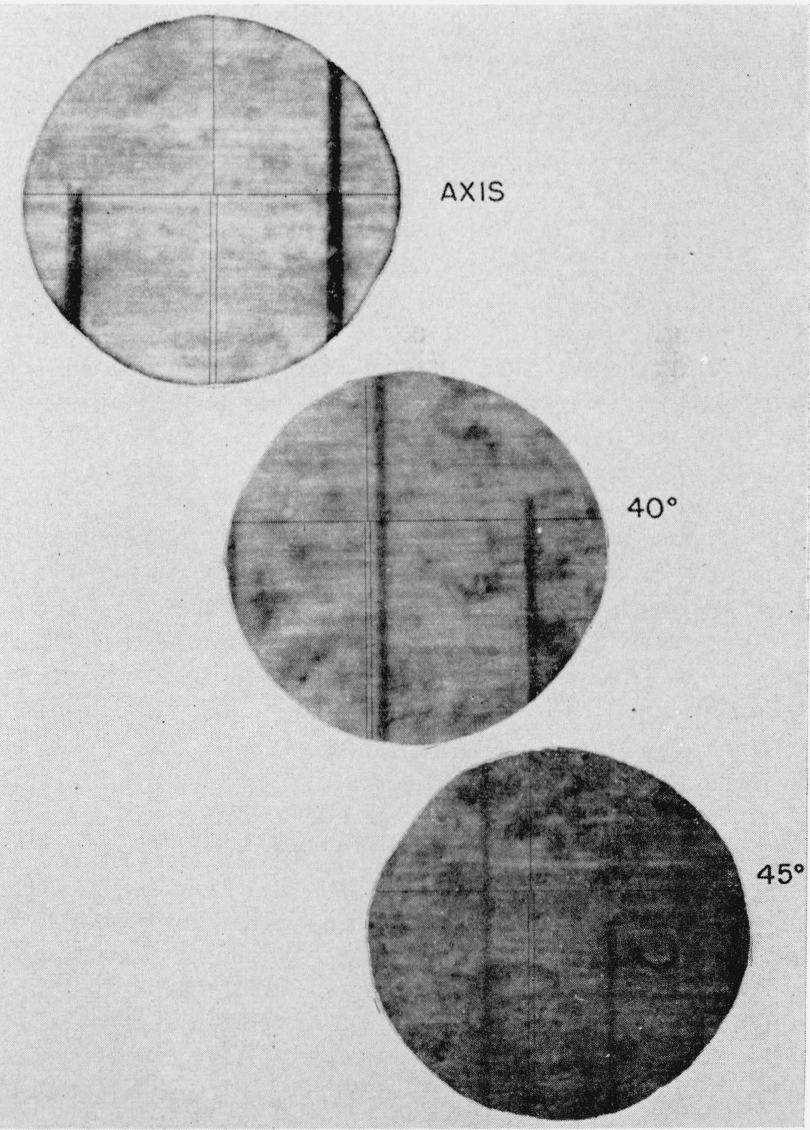

Figure 4. Scale of the meter bar as seen through the viewing telescope. 
TABLE 2. Measured values in the object space of the angular separation, $\beta$, from the axis corresponding to the $10 \mathrm{~mm}$ intervals of a standard scale located in the focal plane of wide angle lens No. 3

Values are shown for corresponding positions along the same diameter to the right and left of axis. The position of the theodolite for each series of settings is indicated by the bench scale readings. The change in the value of $\boldsymbol{\beta}$ that occurs on shifting of the theodolite position is shown under $\Delta \beta$.

\begin{tabular}{|c|c|c|c|c|c|c|c|}
\hline \multicolumn{4}{|c|}{ Right } & \multicolumn{4}{|c|}{ Left } \\
\hline $\begin{array}{l}\text { Bench } \\
\text { scale }\end{array}$ & $\begin{array}{c}\text { Meter } \\
\text { bar }\end{array}$ & $\begin{array}{c}\text { Angular } \\
\text { separa- } \\
\text { tion, } \beta \text {, } \\
\text { from axis }\end{array}$ & $\Delta \beta$ & $\begin{array}{l}\text { Bench } \\
\text { scale }\end{array}$ & $\begin{array}{c}\text { Meter } \\
\text { bar }\end{array}$ & $\begin{array}{l}\text { Angular } \\
\text { separa- } \\
\text { tion, } \beta \text {, } \\
\text { from axis }\end{array}$ & $\Delta \beta$ \\
\hline $\begin{array}{c}m m \\
569.0\end{array}$ & $\begin{array}{r}m m \\
0 \\
10 \\
20 \\
30\end{array}$ & $\begin{array}{r}\text { deg } \\
0.0000 \\
3.7523 \\
7.4585 \\
11.1039\end{array}$ & $d e g$ & $\begin{array}{l}m m \\
569.0\end{array}$ & $\begin{array}{r}m m \\
0 \\
i 0 \\
20 \\
30\end{array}$ & $\begin{array}{r}\text { deg } \\
0.0000 \\
3.7535 \\
7.4829 \\
11.1729\end{array}$ & deg \\
\hline 498.5 & $\begin{array}{l}30 \\
40 \\
50 \\
60 \\
70 \\
80 \\
90\end{array}$ & $\begin{array}{l}11.1058 \\
14.6558 \\
18.0686 \\
21.3551 \\
24.4945 \\
27.4799 \\
30.3061\end{array}$ & & 639.0 & $\begin{array}{l}30 \\
40 \\
50 \\
60 \\
70 \\
80 \\
90\end{array}$ & $\begin{array}{l}11.1449 \\
14.7417 \\
18.2166 \\
21.5645 \\
24.7641 \\
27.8161 \\
30.7400\end{array}$ & -0.0280 \\
\hline 427.3 & $\begin{array}{r}90 \\
100 \\
110 \\
120 \\
130\end{array}$ & $\begin{array}{l}30.3269 \\
32.9835 \\
35.4940 \\
37.8604 \\
40.0879\end{array}$ & 0.0208 & 708.0 & $\begin{array}{r}90 \\
100 \\
110 \\
120 \\
130\end{array}$ & $\begin{array}{l}30.7019 \\
33.4457 \\
36.0266 \\
38.4541 \\
40.7390\end{array}$ & -0.0381 \\
\hline 378.4 & $\begin{array}{l}130 \\
140 \\
150 \\
160\end{array}$ & $\begin{array}{l}40.1064 \\
42.1921 \\
44.1553 \\
45.9564\end{array}$ & 0.0180 & 754.4 & $\begin{array}{l}130 \\
140 \\
150 \\
160\end{array}$ & $\begin{array}{l}40.7284 \\
42.8877 \\
44.8924 \\
46.7749\end{array}$ & -0.0100 \\
\hline
\end{tabular}

of the lens. Consequently for a single location of the theodolite on its bench it is possible to make settings on a comparatively few divisions of the scale located in the focal plane of the lens under test before vignetting cuts off the view. This is indicated in table 2 , where the successive readings of the bench scale show that the theodolite occupied seven different positions to cover an angular range of $\beta=46^{\circ}$ to the right and left of axis. When the theodolite is moved from one position to another along its bench, it is customary to make the first setting of the new position on the same line of the meter bar as the last setting of the former position. This is indicated in table 2 by the double entries for meter bar divisions 30,90, and 130 . The angular values obtained for these double entries do not coincide but show differences of varying amounts which are tabulated under the caption $\Delta \beta$. If it is assumed that the theodolite always is moved parallel to itself, these differences $\Delta \beta$ should equal zero. The alternative explanations are: (1) Curvature of the bench ways and (2) aberrations arising from an asymmetrical use of aperture. If the second cause is regarded as negligible, then subtracting the decrement, $\Delta \beta$, from the observed values of $\beta$ should eliminate any errors arising from (1). This was done and the values of $\beta$ so determined are given in table 3 . This table also shows the values of equivalent focal length and distortion, $D_{R}$, to right of axis and $D_{L}$ to the left of axis.

The values of distortion in table 3 are not directly comparable in the form shown to those given in table 1. Consequently it was necessary to evaluate $D_{R}$ and $D_{L}$ for values of $\beta$ at $5^{\circ}$ intervals. This was done by linear interpolation and the values are
TABLE 3. Values of the distortion, $\mathrm{D}_{\mathrm{R}}$ and $\mathrm{D}_{\mathrm{L}}$, referred to the equivalent focal length $(\mathrm{f}=152.518 \mathrm{~mm})$, based on the measurements shown in table 2

Values of $\beta$ are adjusted by adding the measured values of $\Delta \beta$ to the measured values of $\beta$ for each bench setting.

\begin{tabular}{|c|c|c|c|c|c|c|c|}
\hline \multicolumn{4}{|c|}{ Right } & \multicolumn{4}{|c|}{ Left } \\
\hline $\begin{array}{c}\text { Meter } \\
\text { bar }\end{array}$ & $\beta$ & $f \tan _{\beta}$ & $D_{R}$ & $\begin{array}{c}\text { Meter } \\
\text { bar }\end{array}$ & $\beta$ & $f \tan _{\beta}$ & $D_{L}$ \\
\hline$m m$ & deg & $\mathrm{mm}$ & $m m$ & $m m$ & deg & $\mathrm{mm}$ & $m m$ \\
\hline 0 & 0.0000 & 0.000 & 0.000 & 0 & 0.0000 & 0.000 & 0.000 \\
\hline 10 & 3. 7523 & 10.003 & -.003 & 10 & 3.7535 & 10.006 & -.006 \\
\hline 20 & 7. 4585 & 19. 967 & .003 & 20 & 7. 4829 & 20.033 & -.033 \\
\hline 30 & 11. 1039 & 29. 933 & .067 & 30 & 11. 1729 & 30.124 & -.124 \\
\hline 40 & 14. 6539 & 39.881 & .119 & 40 & 14. 7697 & 40.210 & -.210 \\
\hline 50 & 18. 0667 & 49. 752 & .248 & 50 & 18. 2446 & 50.277 & -.277 \\
\hline 60 & 21. 3532 & 59.627 & .373 & 60 & 21. 5925 & 60.363 & -.363 \\
\hline 70 & 24. 4926 & 69.482 & .518 & 70 & 24. 7921 & 70.447 & -.447 \\
\hline 80 & 27.4780 & 79. 321 & .679 & 80 & 27.8441 & 80.563 & -.563 \\
\hline 90 & 30.3042 & 89.139 & .861 & 90 & 30.7680 & 90.803 & -.803 \\
\hline 100 & 32.9608 & 98.897 & 1. 103 & 100 & 33.5118 & 100.994 & -.994 \\
\hline 110 & 35.4713 & 108. 674 & 1. 326 & 110 & 36. 0927 & 111.188 & -1.188 \\
\hline 120 & 37.8377 & 118.465 & 1.535 & 120 & 38.5202 & 121.405 & -1.405 \\
\hline 130 & 40.0652 & 128.273 & 1. 727 & 130 & 40.8051 & 131.673 & -1.673 \\
\hline 140 & 42. 1509 & 138.056 & 1. 944 & 140 & 42. 9644 & 142.047 & -2.047 \\
\hline 150 & 44. 1141 & 147.872 & 2. 128 & 150 & 44. 9691 & 152.353 & -2.353 \\
\hline 160 & 45.9152 & 157.469 & 2. 531 & 160 & 46.8516 & 162.707 & -2.707 \\
\hline
\end{tabular}

TABLE 4. Values of the distortion, $\mathrm{D}_{\mathrm{E}}$ and $\mathrm{D}_{\mathrm{C}}$ for wide angle lens No. 3 for values of $\beta$ varying in $5^{\circ}$ steps

These values are derived from table 3 .

\begin{tabular}{|c|c|c|c|c|c|c|c|}
\hline$\beta$ & $D_{R}$ & $D_{L}$ & $D_{E}$ & $\Delta f \tan \beta$ & $D_{C}^{\prime}$ & $\Delta D_{T}$ & $D_{C}$ \\
\hline deg & $m m$ & $m m$ & $m m$ & $\mathrm{~mm}$ & & & \\
\hline 0 & 0.000 & 0. 000 & 0.000 & 0.000 & 0.000 & 0.000 & 0.000 \\
\hline 5 & .009 & -.015 & -.003 & .004 & -.007 & -.003 & -.004 \\
\hline 10 & .057 & -.095 & -.019 & . ก08 & -.027 & -.005 & -.022 \\
\hline 15 & $\begin{array}{l}.132 \\
.290\end{array}$ & -.214 & -.041 & .012 & -.053 & -.007 & -.046 \\
\hline 20 & .322 & -.322 & .000 & .016 & -.016 & -.009 & -.007 \\
\hline 25 & .545 & -.455 & .045 & .020 & .025 & -.010 & .035 \\
\hline 30 & .841 & -.740 & $.05 t$ & .025 & .02 & -.010 & .035 \\
\hline 35 & 1. 284 & -1.106 & .089 & .030 & $\begin{array}{l}.059 \\
.02\end{array}$ & -.007 & .066 \\
\hline 40 & 1. 721 & -1.579 & .071 & .036 & .035 & .003 & .032 \\
\hline 45 & 2. 326 & -2.359 & -.016 & .043 & -.059 & .007 & -.066 \\
\hline
\end{tabular}

shown in table 4 . The asymmetry of the distortion pattern results from a small tilting of the scalebar with respect to the focal plane of the lens. This effect can be readily compensated at the proper stage by computation. ${ }^{4}$ The value of the distortion, $D_{E}$, referred to the equivalent focal length is given by the relation

$$
D_{E}=\frac{D_{R}+D_{L}}{2}
$$

Values of $D^{\prime}{ }_{C}$, the distortion referred to the calibrated focal length are derived from $D_{E}$ in the usual manner. Finally these values are corrected with the aid of the equation

$$
D_{C}=D_{C}^{\prime}-\Delta D_{T},
$$

where $\Delta D_{T}$ is the correction for the tilt of the scale bar and $D_{C}$ is the value of the distortion referred to

4 F. E. Washer, Sources of error in various methods of airplane camer a calibration, Photogrammetric Eng., XXII, 727 (1956). 
the calibrated focal length which is accepted as the best value obtainable by this method of analysis. Comparison of the values of $D_{C}$ shown in table 4 with the values of the average $\overline{D_{3}}$ for methods $\mathrm{A}, \mathrm{B}$, and $\mathrm{D}$ given in table 1 shows marked disagreement. The disparity between corresponding values is so great that it is apparent that the measurements are being affected by some uncompensated source of error.

It seems probable that the aberrations arising from asymmetrical use of apertures contribute heavily to the observed disparities. With this in mind it seemed worthwhile to neglect errors arising from bench curvature and to attempt to reduce the aberration effects by averaging the value of $\beta$ in the double-entry regions of table 3 on the hypothesis that the two separate values were obtained for opposite conditions of vignetting and that the average might approximate the value obtained for centered apertures. This was accordingly done and the values of $\beta$ so determined are listed in table 5 . No adjustment was made for those values of $\beta$ at the nontransition points. The values of distortion are computed and are shown in table $5 . \quad D_{R}$ and $D_{L}$ are evaluated at $5^{\circ}$ intervals and are tabulated in table 6 , together with $D_{E}$ and $D_{C}$. The values of $D_{C}$ obtained in this manner are nearer to the values shown in table 1 than are the values given in table 4 which indicates that this method of reducing the data is superior to the method used in deriving table 4. The disparities that remain are due in part to some noncompensated bench curvature and in part to observation arising from unsymmetrical use of apertures. On making an adjustment, $\Delta D$, for the error arising from the measured departure of

$\mathrm{T}_{\mathrm{ABLE}} 5$. Values of the distortion, $\mathrm{D}_{\mathrm{R}}$ and $\mathrm{D}_{\mathrm{L}}$, referred to the equivalent focal length $(\mathrm{f}=152.518 \mathrm{~mm})$ based on the measurements shown in table 2

No adjustment if made for the values of $B$ except to average the two values of $\boldsymbol{\beta}$ at each transition point.

\begin{tabular}{|c|c|c|c|c|c|c|c|}
\hline \multicolumn{4}{|c|}{ Right } & \multicolumn{4}{|c|}{ Left } \\
\hline $\begin{array}{c}\text { Meter } \\
\text { bar }\end{array}$ & $\begin{array}{l}\text { Angular } \\
\text { separa- } \\
\text { tion } \\
\text { from } \\
\text { axis }\end{array}$ & $f \tan \beta$ & $D_{R}$ & $\begin{array}{c}\text { Meter } \\
\text { bar }\end{array}$ & $\begin{array}{l}\text { Angular } \\
\text { separa- } \\
\text { tion } \\
\text { from } \\
\text { axis }\end{array}$ & $f \tan \beta$ & $D_{L}$ \\
\hline $\begin{array}{r}m m \\
0 \\
10 \\
20 \\
30\end{array}$ & $\begin{array}{r}\text { deg } \\
0.0000 \\
3.7523 \\
7.4585 \\
11.1048\end{array}$ & $\begin{array}{l}m m \\
0.000 \\
10.003 \\
19.967 \\
29.936\end{array}$ & $\begin{array}{l}m m \\
0.000 \\
-.003 \\
+.033 \\
+.064\end{array}$ & $\begin{array}{r}m m \\
0 \\
10 \\
20 \\
30\end{array}$ & $\begin{array}{r}\text { deg } \\
0.0000 \\
3.7535 \\
7.4829 \\
11.1589\end{array}$ & $\begin{array}{c}m m \\
0.000 \\
10.006 \\
20.033 \\
30.086\end{array}$ & $\begin{array}{l}m m \\
0.000 \\
-.006 \\
-.033 \\
-.086\end{array}$ \\
\hline $\begin{array}{l}40 \\
50 \\
60 \\
70 \\
80 \\
90\end{array}$ & $\begin{array}{l}14.6558 \\
18.0586 \\
21.3551 \\
24.4945 \\
27.4799 \\
30.3165\end{array}$ & $\begin{array}{l}39.887 \\
49.758 \\
59.633 \\
69.489 \\
79.328 \\
89.183\end{array}$ & $\begin{array}{l}.113 \\
.242 \\
.367 \\
.511 \\
.672 \\
.817\end{array}$ & $\begin{array}{l}40 \\
50 \\
60 \\
70 \\
80 \\
90\end{array}$ & $\begin{array}{l}14.7417 \\
18.2166 \\
21.5645 \\
24.7641 \\
27.8161 \\
30.7210\end{array}$ & $\begin{array}{l}40.131 \\
50.194 \\
60.277 \\
70.357 \\
80.468 \\
90.634\end{array}$ & $\begin{array}{l}-.131 \\
-.194 \\
-.277 \\
-.357 \\
-.468 \\
-.634\end{array}$ \\
\hline $\begin{array}{l}100 \\
110 \\
120 \\
130\end{array}$ & $\begin{array}{l}32.9835 \\
35.4940 \\
37.8601 \\
40.0972\end{array}$ & $\begin{array}{r}98.984 \\
108.766 \\
118.563 \\
128.419\end{array}$ & $\begin{array}{l}1.016 \\
1.234 \\
1.437 \\
1.581\end{array}$ & $\begin{array}{l}100 \\
110 \\
120 \\
130\end{array}$ & $\begin{array}{l}33.4457 \\
36.0266 \\
38.4541 \\
40.7337\end{array}$ & $\begin{array}{l}100.742 \\
110.919 \\
121.162 \\
131.342\end{array}$ & $\begin{array}{r}-.742 \\
-.819 \\
-1.162 \\
-1.342\end{array}$ \\
\hline $\begin{array}{l}140 \\
150 \\
160\end{array}$ & $\begin{array}{l}42.1921 \\
44.1553 \\
45.9564\end{array}$ & $\begin{array}{l}138.257 \\
148.086 \\
157.697\end{array}$ & $\begin{array}{l}1.743 \\
1.914 \\
2.303\end{array}$ & $\begin{array}{l}140 \\
150 \\
160\end{array}$ & $\begin{array}{l}42.8878 \\
44.8924 \\
46.7749\end{array}$ & $\begin{array}{l}141.668 \\
151.945 \\
162.272\end{array}$ & $\begin{array}{l}-1.668 \\
-1.945 \\
-2.272\end{array}$ \\
\hline
\end{tabular}

TABLE 6. Values of the distortion, $\mathrm{D}_{\mathrm{R}}$ and $\mathrm{D}_{\mathrm{L}}$ for wide angle lens No. 3 for values of $\beta$ varying in $5^{\circ}$ steps

The values of $D_{E}$ (distortion referred to the equivalent focal length) and $D_{C}$ (distortion referred to the calibrated focal lengtt. ) are also given together with the adjustment of pointing error $\Delta D_{E}$ and the final value of distortion for the method, $D_{F}$. These values are derived from table 5 .

\begin{tabular}{|c|c|c|c|c|c|c|c|}
\hline$\beta$ & $D_{R}$ & $D_{L}$ & $D_{E}$ & $\Delta f \tan \beta$ & $D_{C}$ & $\Delta D_{E}$ & $D_{F}$ \\
\hline deg & $m m$ & $m m$ & $m m$ & $m m$ & $m m$ & $m m$ & $m m$ \\
\hline 0 & 0.000 & 0.000 & 0.000 & 0.000 & 0.000 & 0.000 & 0.000 \\
\hline 5 & .010 & -.015 & -.002 & -.009 & -.011 & .003 & -.008 \\
\hline 10 & .055 & -.069 & -.007 & -.019 & -.026 & .005 & -.021 \\
\hline 15 & .126 & -.136 & -.005 & -.029 & -.034 & .007 & -.027 \\
\hline 20 & .316 & -.238 & .039 & -.039 & .000 & .010 & .010 \\
\hline 25 & .538 & -.366 & .086 & -.050 & .036 & .010 & .046 \\
\hline 30 & 801 & -.608 & .096 & -.062 & .034 & .010 & .044 \\
\hline 35 & 1.191 & -.849 & .171 & -.076 & .095 & .006 & .101 \\
\hline 40 & 1.575 & -1.284 & .146 & -.091 & .055 & -.002 & .053 \\
\hline 45 & 1. 988 & -1.964 & .012 & -.108 & -.096 & -.006 & -.102 \\
\hline
\end{tabular}

the bench from straightness, the value $D_{F}$ represents a value free from error arising from bench curvature. This value, $D_{F}$, is still somewhat different from the average given in table 1 showing that the aperture error is appreciable.

\subsection{Errors Arising From Asymmetric Apertures}

In an earlier paper (see footnote 3), an extended discussion of the effect of asymmetrical apertures is given. It is evident from a consideration of the arrangement of apparatus used in the modified goniometer method that the apertures are being used asymmetrically for most settings. To show that this is so, a series of photographs of the effective aperture of the lens under test as seen in the exit pupil of the viewing telescope was made. Some of these photographs are reproduced in figure 5. The dark circles indicate the exit pupil of the telescope; the light circles or ovals show the effective aperture of the lens under test as seen in the exit pupil; and the irregular light areas are caused by random reflections of stray light hitting the interior walls of the telescope tube. The principal interest in these photographs is to note the different relative positions of the lens aperture as seen in the exit pupil. Referring to table 1 , it may be noted that for bench scale reading $569 \mathrm{~mm}$, and for meter bar reading of $30 \mathrm{~mm}$, the aperture is at the right side of the pupil and partially obscured while for the second entry of 30 $\mathrm{mm}$ at bench scale reading of $639 \mathrm{~mm}$, the aperture is at the left of the pupil and cut even more. The difference in $\beta$ for these settings is $0.0280^{\circ}$. Similar conditions exist for meter bar readings of 90 and 130 . It is obvious that in proceeding from meter bar reading +30 to -30 the lens aperture is centered for only one setting at $0 \mathrm{~mm}$, and an asymmetric condition exists at all other positions in the range from +30 to -30 . One would expect that values of the distortion obtained under these conditions would show large random variations from the true value. This is indicated in table 7 which shows a comparison between values of $\bar{D}_{3}$ from table 1 and method $\mathrm{F}$ from table 6 . 


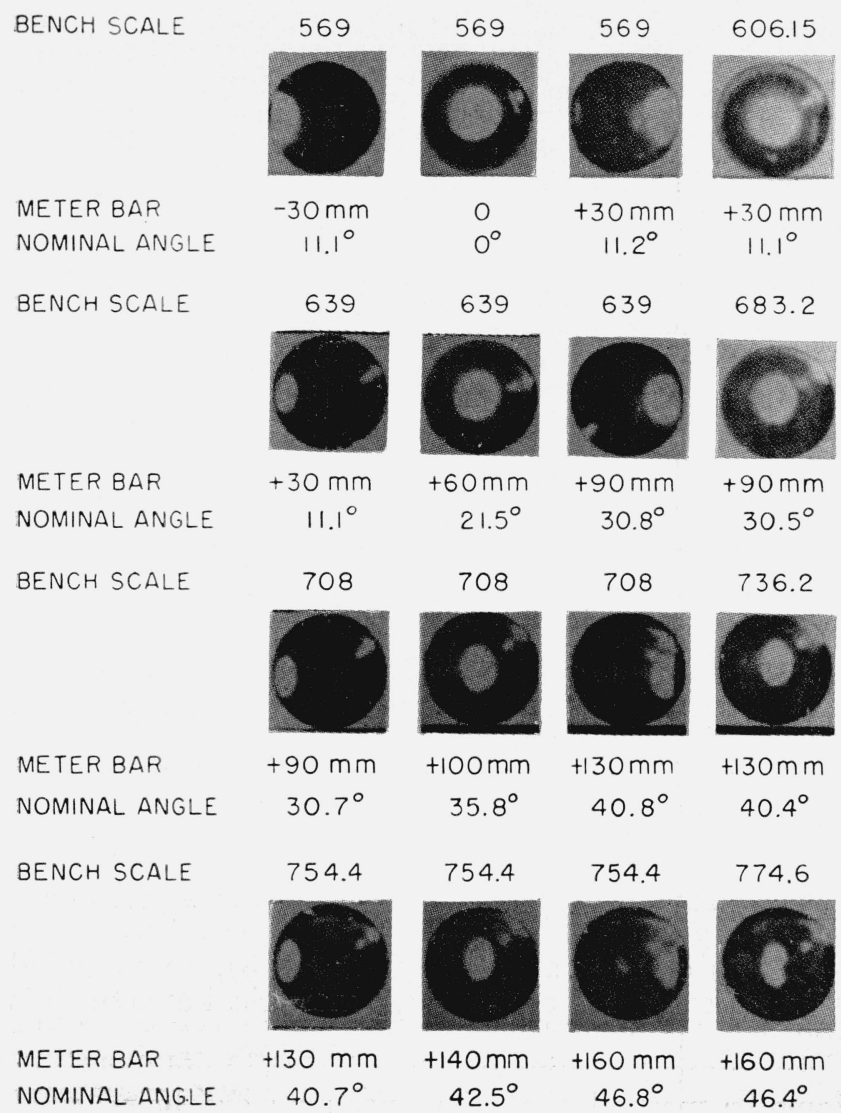

FIGURE 5. Photographs showing the relative position of the effective aperture of the lens under test in the exit pupil of the measuring telescope for a series of bench and meter bar readings.

TABLE 7. Comparison of the values of distortion $\mathrm{D}_{\mathrm{F}}$ obtained by method $F$ from table 6 with the average values $\overline{\mathbf{D}}_{3}$ from table 1

For these values of $D_{F}$, the exit apertures of the lens and entrance aperture of the telescope are centered for values of $\beta$ near $0^{\circ}, 23^{\circ}, 36^{\circ}$, and $44^{\circ}$. All values are in microns.

\begin{tabular}{|c|c|c|c|}
\hline$\beta$ & $\bar{D}_{2}$ & $D_{F}$ & $\Delta D=\overline{D_{3}}-D_{F}$ \\
\hline $\begin{array}{r}\text { deg } \\
0 \\
5 \\
10 \\
15 \\
20\end{array}$ & $\begin{array}{r}0 \\
-6 \\
-6 \\
3 \\
23\end{array}$ & $\begin{array}{r}0 \\
-8 \\
-21 \\
-27 \\
10\end{array}$ & $\begin{array}{r}0 \\
2 \\
15 \\
30 \\
13\end{array}$ \\
\hline $\begin{array}{l}25 \\
30 \\
35 \\
40 \\
45\end{array}$ & $\begin{array}{r}53 \\
86 \\
109 \\
78 \\
-109\end{array}$ & $\begin{array}{r}46 \\
44 \\
101 \\
53 \\
-102\end{array}$ & $\begin{array}{r}7 \\
42 \\
8 \\
25 \\
-7\end{array}$ \\
\hline
\end{tabular}

\subsection{Method of Eliminating Effect of Unsymmetrical Apertures}

The improvement in reliability of results shown in table 6 over those shown in table 4 appeared to warrant additional measurements using a method calculated to minimize any effects arising from unsymmetrical use of apertures. Accordingly new measurements were made which are given in table
8. In these measurements, it is assumed that the movement along the crossbench does not alter the reliability of the angle measurements, so the theodolite was displaced for each setting in such a manner that the exit aperture of the lens under test appeared centered in the exit pupil of the telescope. The appearance of the exit pupil is shown in the right hand column for a few cases in figure 5. Each setting was repeated 5 times so as to determine the probable error of the mean for each value of $\beta$. The probable error of the mean for the values of $\beta$ was found to be approximately \pm 2 seconds which corresponds to a maximum error in the distortion values of $\pm 0.003 \mathrm{~mm}$.

The values of the distortion, $D_{R}$ and $D_{L}$, were determined from the measured values of $\beta$ corresponding to the scale divisions of the meter bar and are given in table 8 . These values were used to determine the values of $D_{E}$ (distortion referred to the equivalent focal length) at $5^{\circ}$ intervals which are given in table 9 . This table also shows the values of $D_{C}$ (distortion referred to the calibrated focal length). While the error arising from bench curvature was assumed to be negligible, it is known that this is not quite true. However, the magnitude of this error has been measured for each position occupied by the theodolite and an appropriate correction is made under the caption $\Delta D_{E}$ (compensation for pointing error). Finally the value of $D_{F}$ is shown in the last column.

Comparison of the values of $D^{\prime}{ }_{F}$ from table 9 with that of $\bar{D}_{3}$ from table 1 is shown in table 10 together with the difference $\bar{D}_{3}-D_{F}^{\prime}$. Consideration of the values of $\bar{D}_{3}-D_{F^{\prime}}^{\prime}$ leads to the belief that systematic error of some sort is still present. A possible source is curvature of the meter bar.

TABLE 8. Measured values in the object space of the angular separation, $\beta$, from the axis corresponding to $10 \mathrm{~mm}$ intervals of a standard scale located in the focal plane of wide angle lens No. 3

Conditions the same as for table 2, except apertures are centered for each setting. Each value of $\beta$ is the average of 5 settings; the average probable error of the mean is $\pm 0.0056^{\circ}$ or 2.0 seconds which corresponds to a maximum distortion error of $\pm 0.003 \mathrm{~mm}$. The values of the distortion are also shown.

\begin{tabular}{|c|c|c|c|c|c|c|c|}
\hline \multicolumn{4}{|c|}{ Righi } & \multicolumn{4}{|c|}{ Left } \\
\hline $\begin{array}{l}\text { Bench } \\
\text { scale }\end{array}$ & $\begin{array}{c}\text { Meter } \\
\text { bar }\end{array}$ & $\beta$ & $D_{R}$ & $\begin{array}{l}\text { Bench } \\
\text { scale }\end{array}$ & $\begin{array}{l}\text { Meter } \\
\text { bar }\end{array}$ & $\beta$ & $D_{L}$ \\
\hline$m m$ & $m m$ & $d e g$ & $m m$ & $m m$ & $m m$ & $d e g$ & $m m$ \\
\hline 569.8 & 0 & 0.0000 & 0.000 & 569.8 & 0 & 0.0000 & 0.000 \\
\hline 556.6 & 16 & 3.7523 & -.002 & 581.2 & 10 & 3. 7498 & .004 \\
\hline 544.4 & 20 & 7.4715 & -.001 & 594.3 & 20 & 7.4706 & .001 \\
\hline 531.8 & 30 & 11.1260 & .007 & 606.2 & 30 & 11.1265 & .005 \\
\hline 519.1 & 40 & 14.6887 & .022 & 619.9 & 40 & 14. 6912 & .015 \\
\hline 505.6 & 50 & 18.1375 & .041 & 633.2 & 50 & 18. 1414 & .030 \\
\hline 495.2 & 60 & 21. 4549 & .063 & 645. 6 & 60 & 21. 4586 & .052 \\
\hline 480.8 & 70 & 24.6261 & .091 & 658.2 & 70 & 24. 6313 & .074 \\
\hline 469.1 & 80 & 27.6430 & .123 & 669.9 & 80 & 27. 6492 & .102 \\
\hline 456.8 & 90 & 30.5027 & .154 & 683.2 & 90 & 30.5093 & .131 \\
\hline 443.3 & 100 & 33.2041 & .184 & 697.0 & 100 & 33.2108 & .159 \\
\hline 431.4 & 110 & 35. 7521 & .199 & 709.4 & 110 & 35. 7592 & .175 \\
\hline 419.5 & 120 & 38.1506 & .198 & 724.0 & 120 & 38.1544 & .182 \\
\hline 406.5 & 130 & 40.4028 & .190 & 736.2 & 130 & 40.4095 & .159 \\
\hline 393.4 & 140 & 42.5212 & .146 & 751.5 & 140 & 42.5304 & .100 \\
\hline 380.0 & 150 & 44.5066 & .093 & 762.4 & 150 & 41. 5245 & .000 \\
\hline 367.7 & 160 & 46. 3712 & .009 & 774.6 & 160 & 46. 3968 & -.134 \\
\hline
\end{tabular}


TABLE 9. Values of the distortion $\mathrm{D}_{\mathrm{R}}, \mathrm{D}_{\mathrm{L}}$, and $\mathrm{D}_{\mathrm{E}}$ derived from table 8

The values of $D_{C}$, the distortion referred to the ealibrated focal length and the values of $D^{\prime} P$ derived from $D_{C}$ after compensation for pointing error $\Delta D_{E}$ are also shown. All values are in microns.

\begin{tabular}{|c|c|c|c|c|c|c|c|}
\hline$\varepsilon$ & $D_{R}$ & $D_{L}$ & $\frac{D_{E}=D_{R}+D_{L}}{2}$ & $\Delta f \tan B$ & $D_{C}$ & $\Delta D_{H}$ & $D_{F}^{\prime}$ \\
\hline deg & & & & & & & \\
\hline 0 & 0 & 0 & 0 & 0 & 0 & 0 & 0 \\
\hline 5 & -2 & 3 & 0 & 10 & -10 & 3 & -7 \\
\hline 10 & 5 & 4 & 4 & 21 & -17 & 5 & -12 \\
\hline 15 & 24 & 16 & 20 & 32 & -12 & 7 & -5 \\
\hline 20 & 53 & 42 & 48 & 43 & 5 & 10 & 15 \\
\hline 25 & 95 & 77 & 86 & 55 & 31 & 10 & 41 \\
\hline 30 & 149 & 126 & 138 & 68 & 70 & 10 & 80 \\
\hline 35 & 195 & 170 & 182 & 83 & 99 & 6 & 105 \\
\hline 40 & 191 & 163 & 177 & 99 & 78 & -2 & 76 \\
\hline 45 & 71 & -34 & 18 & 118 & -100 & -6 & -106 \\
\hline
\end{tabular}

TABLE 10.-Comparison of the values of $\mathrm{D}_{\mathrm{F}}^{\prime}$ from table 9 with $\overline{\mathrm{D}}_{3}$ from table 1

The magnitude of the correction $D_{C}$ required to compensate assumed curvature of target scale (sagitta $=22 \mu$ ) and final accepted value $D_{F}$ for method $F$ are also shown. All values are in microns.

\begin{tabular}{|c|c|c|c|c|c|}
\hline$\beta$ & $\bar{D}_{3}$ & $D_{F}^{\prime}$ & $\bar{D}_{3}-D_{F}^{\prime}$ & $\Delta D_{C}$ & $\begin{array}{l}D_{F}= \\
D_{F}^{\prime}+D_{C}\end{array}$ \\
\hline \multicolumn{6}{|l|}{ deg } \\
\hline 0 & 0 & 0 & 0 & 0 & 0 \\
\hline 5 & -6 & -7 & 1 & 2 & -5 \\
\hline 10 & -6 & -12 & 6 & 3 & -9 \\
\hline 15 & 3 & -5 & 8 & 4 & -1 \\
\hline 20 & 23 & 15 & 8 & 5 & 20 \\
\hline 25 & 53 & 41 & 12 & 6 & 47 \\
\hline 30 & 86 & 80 & 6 & 6 & 86 \\
\hline 35 & 109 & 105 & 4 & 5 & 110 \\
\hline 40 & & 76 & 2 & 2 & 78 \\
\hline 45 & -109 & -106 & -3 & -5 & -111 \\
\hline
\end{tabular}

A computation was made, to determine the probable magnitude of the assumed curvature (see footnote 4). A value of $22 \mu$ for the sagitta of the curve seemed satisfactory and reasonable and is used to determine the values of $\Delta D_{C}$. The value of $D_{F}$ shows the effect of making this correction and is accepted as the best set of values of distortion obtained by method F.

\subsection{Review of Results Obtained by Four Different Methods}

In the course of this investigation, extended series of measurement of the values of radial distortion have been made on a single lens using four distinctly different methods designated A, B, D, and F. Table 11 shows, in section (a), the final value accepted for each method together with the average for the four. Part (b) of table 11 shows the departure from the average for each of the four methods together with the probable error of a single determination for a given method with respect to the average for all methods. The departure from the average for each of the four methods is also shown in figure 6 . In the course of the investigation, it has been shown that the $P E_{s}$ for values obtained by any one of the methods is approximately $\pm 3 \mu$. It is shown in table 11, that the departure of the
TABLE 11. Measured values of the distortion in microns referred to the calibrated focal length for wide angle lens No. 3 for four different methods

The values for $\mathrm{A}, \mathrm{B}, \mathrm{D}$, and $\mathrm{F}$ in part $\mathrm{A}$ are the final accepted values obtained by each of the four methods. Departures from the average $\bar{D}$ for the four are shown in part (b) together with the value of $P E_{s}$, the probable error for values obtained by a single method.

\begin{tabular}{|c|c|c|c|c|c|}
\hline \multirow{2}{*}{$\begin{array}{c}\text { Angular } \\
\text { separation } \\
\text { from axis } \\
\beta\end{array}$} & \multicolumn{4}{|c|}{ (a) Values of distortion obtained by method } & \multirow{2}{*}{$\frac{\text { Average }}{\mathrm{D}}$} \\
\hline & A & B & 1) & $\mathrm{F}$ & \\
\hline 0 & 0 & 0 & 0 & 0 & 0 \\
\hline 5 & -5 & -7 & -5 & -5 & -6 \\
\hline 10 & -5 & -8 & -6 & -9 & -7 \\
\hline 15 & 4 & 1 & 4 & -1 & 2 \\
\hline 20 & 21 & 21 & 26 & 20 & 22 \\
\hline 25 & 49 & 52 & 58 & 47 & 52 \\
\hline 30 & 82 & 87 & 90 & 86 & 86 \\
\hline 35 & 113 & 106 & 108 & 110 & 109 \\
\hline 40 & 79 & 79 & 77 & 78 & 78 \\
\hline 45 & -113 & -106 & -108 & -111 & -109 \\
\hline
\end{tabular}

(b) Departures from the average for method

\begin{tabular}{|c|c|c|c|c|}
\hline A & B & D & $\mathrm{F}$ & $P E_{s}$ \\
\hline $\begin{array}{r}0 \\
1 \\
2 \\
2 \\
-1\end{array}$ & $\begin{array}{r}0 \\
-1 \\
-1 \\
-1 \\
-1\end{array}$ & $\begin{array}{l}0 \\
1 \\
1 \\
2 \\
4\end{array}$ & $\begin{array}{r}0 \\
1 \\
-2 \\
-3 \\
-2\end{array}$ & $\begin{array}{r} \pm 0 \\
1 \\
1 \\
2 \\
2\end{array}$ \\
\hline $\begin{array}{r}-3 \\
-4 \\
4 \\
1 \\
-4\end{array}$ & $\begin{array}{r}0 \\
1 \\
-3 \\
1 \\
3\end{array}$ & $\begin{array}{r}6 \\
4 \\
-1 \\
-1 \\
1\end{array}$ & $\begin{array}{r}-5 \\
0 \\
1 \\
0 \\
-2\end{array}$ & $\begin{array}{l}3 \\
2 \\
2 \\
1 \\
2\end{array}$ \\
\hline
\end{tabular}

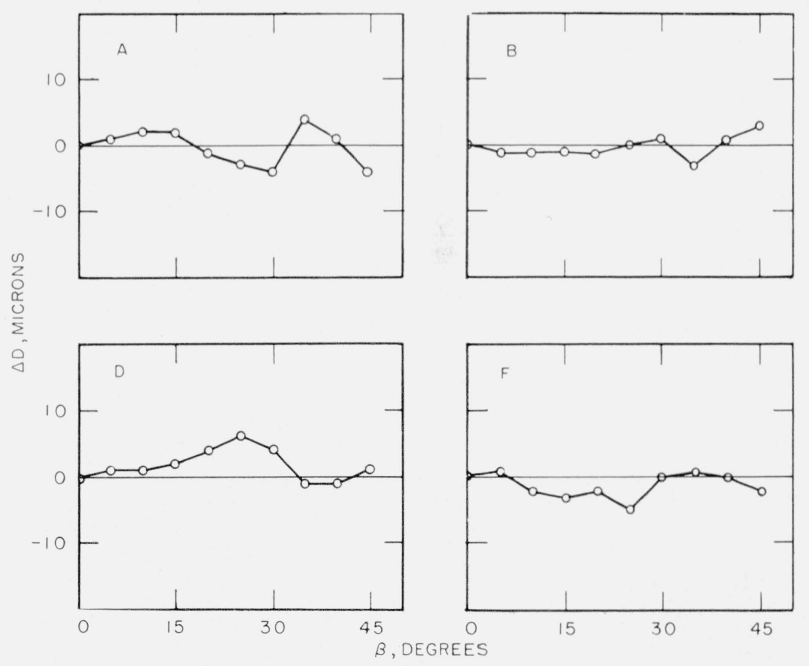

FIgURE 6. Variation of the departures, $\Delta \mathrm{D}$, from the average value of distortion with angular separation $\beta$ from the axis.

The values of $\Delta D$ are computed with respect to the average value of $D$ for the four methods $A, B, D$, and $F$ using the final accepted values for method $F$.

values obtained by a single method from the grand average for four methods does not usually exceed $\pm 3 \mu$.

It can therefore be concluded that the results obtained by any one of these methods are likely to be as good as those obtained by any other of the remaining three methods, and moreover the errors in the values of distortion are unlikely to depart 
by an amount in excess of $\pm 5 \mu$ from the true value. This statement is made on the assumption that proper care is taken in measurements for any of the methods and that all conditions are equivalent.

\section{Conclusions}

While the equivalence of the four methods studied can be regarded as established as a result of these investigations, there are other faetors that are worthy of mention in connection with them. It can be safely stated that method B is the easiest of the methods to use and requires the simplest apparatus, namely nodal slide, visual optical bench, and collimator. It is also relatively easy to understand. Method D is quite easy and simple but more difficult to comprehend because of the inverse manner of the use of the nodal slide. In addition, unusual care is required to insure proper centering of apertures unless a large diameter viewing telescope is used. Method $\mathrm{F}$ while reliable is the most difficult of all. There appear to be more sources of error likely to creep in than for method $\mathrm{B}$ and $\mathrm{D}$, and in addition, it requires more extensive use of trigonometric tables and interpolation than any of the other three methods. Method $\mathrm{A}$ is possibly the easiest to understand. It does however, require complex equipment. It is slower than method $\mathrm{B}$ when there is only one lens to measure. However, as the number of lenses to be tested increases, it becomes more efficient as no time need be lost waiting for negatives to dry before measurement and it is possible to complete measurements on 10 lenses quicker by method $\mathrm{A}$ than by method $\mathrm{B}$. Method $\mathrm{A}$ has, of course, the major advantage that it approximates more nearly conditions of use than any of the other methods.

Washington, D.C.

(Paper 63C2-14) 